\title{
Functional morphology of diatom frustule microstructures: hydrodynamic control of Brownian particle diffusion and advection
}

\author{
Michelle S. Hale*, James G. Mitchell \\ School of Biological Sciences, Flinders University, PO Box 2100, Adelaide, South Australia 5001, Australia
}

\begin{abstract}
While the intricate frustules of diatoms have been well described, understanding of function lags behind that of form. Here, we show that in the presence and absence of tangential flows of up to $800 \mu \mathrm{m} \mathrm{s}^{-1}$, diatom surface microtopographies control the diffusion and advection of submicrometre particles across their surfaces. With no flow, particles were localised on the solid areas of diatom frustules and had reduced diffusion compared to diffusion over flat glass. The magnitude of the effect was dependent on the ratio of the bead radius to the areolae radius $\left(a / R_{0}\right)$. Under flow, particles were deflected from the direction of flow by up to $170^{\circ}$, with over $60 \%$ of particles shifted more than $20^{\circ}$ from the direction of flow. These results suggests that diatom frustules act as particle sorting structures, determining which particles reach the cell membrane and its receptors. This effect has important implications for nutrient uptake and fouling of cells by colloids and particulates, particularly when the particles are much smaller than the areolae. Variations in the hydrodynamic effects of different frustule microstructures on the diffusion and advection of Brownian particles may help explain the diverse range of frustule morphologies observed amongst diatoms.
\end{abstract}

KEY WORDS: Diatom frustules · Particle diffusion · Brownian motion · Functional morphology

\section{INTRODUCTION}

Since the 19th century, the porous, lattice-like silica frustules that encase diatoms have inspired morphologists to carry out detailed descriptions of their form (Greville 1859). Frustules of centric diatoms exhibit surface structures ranging from molecular to microscopic, including radial rows of hexagonal chambers, called areolae (Fig. 1). Each chamber has an outer wall, exposed to the external environment, and an inner wall, close to the cell membrane. It is usual that one of the walls is perforated by a large round hole (foramen), while the other contains a porous plate, called a sieve plate (van der Hoek et al. 1995). The flux of nutrients and exudates across the cell membrane occurs at the base of each areola (the inner wall)

*E-mail: michelle.hale@flinders.edu.au
(Round et al. 1990). The species-specific size, arrangement and structure of areolae have been well described for the 10000 to 12000 known species (Hasle \& Syvertson 1996) and morphology also varies within some species (Babanazarova et al. 1996).

Despite the diversity of frustule structures known to exist, understanding of frustule function is poor. Frustules have been postulated as a defence mechanism against attacks by invasive protozoans (Kühn 1997). Other studies examining frustule function have focused on the long spines produced by some species, which are believed to deter predators (Fogg \& Thake 1987) and either reduce or increase sinking rates (Smayda 1970). While areolae are recognised as the logical location for nutrient flux (Round et al. 1990), there have been no adequate explanations for the morphological diversity observed among coexisting diatoms.

Diatoms are exposed to a range of living and nonliving Brownian particles. In the ocean, they include 

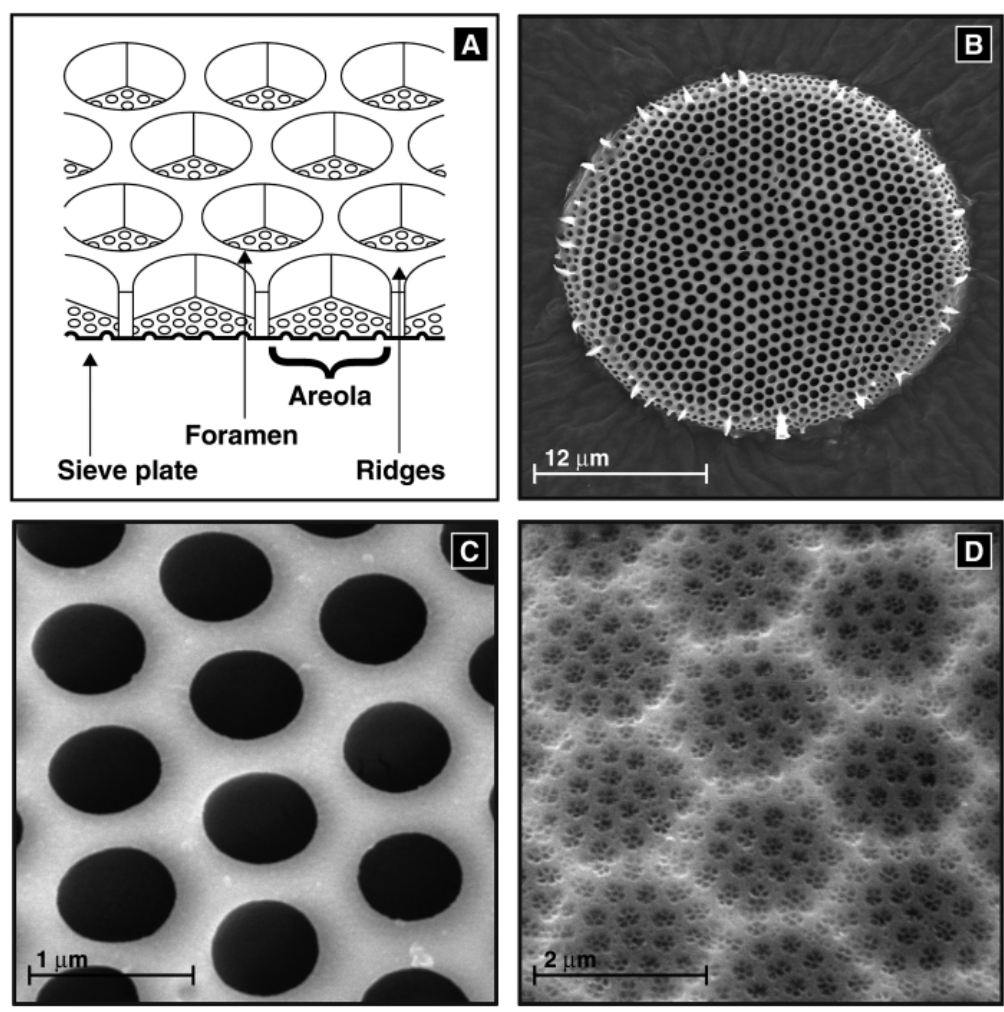

Fig. 1. (A) Schematic representation of frustule structure of a centric diatom, showing the main features of areolae, including the hexagonal structure of each chamber and the presence of a porous sieve plate. Structure and arrangement of areolae within the frustules of centric diatoms are species specific. Scanning electron micrographs of cleaned centric diatom frustules show the areolation patterns of (B, C) Thalassiosira eccentrica and (D) Coscinodiscus sp. Areolae are arranged in regular patterns across the frustule surface (B). In species such as T. eccentrica, areolae open to the external environment (outside) by foramen and open to towards the cell membrane (inside) by a sieve plate. The structure of Coscinodiscus sp. areolae is reversed, with the foramen opening to the inside, and the frustule opening to the outside by a recessed sieve plate

nutrient molecules $\left(\sim 10^{14} \mathrm{ml}^{-1}\right)$, colloids $(5 \mathrm{~nm}$ to $2 \mu \mathrm{m}$ and $\sim 10^{7}$ to $10^{9} \mathrm{ml}^{-1}$; Wells \& Goldberg 1994), viruses (20 to $200 \mathrm{~nm}$; Ackerman \& Dubow 1987) $\sim 10^{7} \mathrm{ml}^{-1}$; Hennes \& Suttle 1995), and bacteria (0.2 to $1 \mu \mathrm{m}$ and $\sim 10^{6} \mathrm{ml}^{-1}$; Ducklow \& Shiah 1993). Given that they are continually bathed in this array and concentration of particles, frustules are remarkably clean surfaces.

Without exterior moving parts or an external layer to continually shed, the mechanisms by which areolae remain open are unknown. At the micro- and nanoscales of single cells and their interactions, interpretations based solely on principles in physics have often been enlightening (Purcell 1977, Vogel 1983). In this case however, principles from subdisciplines in physics provide only hints and have not been applied to the behaviour of particles at the cell-environment interface. Recent advances in nanotechnology and microfluidics have shown that artificially constructed surface patterns can play a role in the behaviour of Brownian particles by altering rates of advection and diffusion close to surfaces (Dinsmore et al. 1996, Duke \& Austin 1998, Chou et al. 1999). This suggests that particle-surface interactions may alter the behaviour of Brownian particles close to frustule microstructures such as areolae. However, particle-surface interactions remain poorly understood and can produce unpredictable or inexplicable results (Feitosa \& Mesquita 1991). While considerable progress has been made for solutions, fluid-particle systems still present significant technical challenges, particularly for seawater where mixtures of complex molecules are common. Previous experiments and models used flat surfaces and the controlling interactions were short-range van der Waals force and longer-range electrostatic force (Song \& Elimelech 1995, Faibish et al. 1998). In cell-fluid systems, ranging from blood to the ocean, high salt concentrations and membranes or other coatings reduce the Debye-Huckel length for electrostatic force to less than a few nanometres (Kaplan et al. 1994). This leaves surface-induced drag on Brownian particles as the dominant process at suprananometre distances from the surface.

For diatoms, the presence of a frustule excludes the formation of structures such as cilia and flagella, and the uptake of large particles. The absence of flagella and cilia, combined with strong ionic screening by seawater, suggests that sorting, breakup or dispersal of these particles occur through drag interactions with the rigid, patterned, surface microstructures. The absence of particle control processes exhibited by other phytoplankton, coupled with the geometric regularity of frustules, make diatoms ideal test systems for examination and experimentation of microstructure-induced particle control by biological surfaces. Diatoms are technically as well as conceptually appealing, as most other biological surfaces are membranaceous, delicate and do not present the single sharp focal plane under light and electron microscopy that frustules do.

Here we show that the microtopographies of diatom frustules alter the diffusion and advection of submicrometre particles, resulting in localised concentrations of particles on ridged areas surrounding areolae. Variations in the hydrodynamic effects of surfaces on the diffusion and advection of Brownian particles may 
help explain the diverse range of frustule morphologies observed amongst diatoms. It appears that passive surface microstructures may control the diffusion of particles near surfaces, hence helping to increase nutrient uptake by reducing areolae fouling.

\section{MATERIALS AND METHODS}

Particle distributions. To examine the effects of areolae on particle movement, live and dead, acid-washed (Hasle \& Fryxell 1970) cells of the diatoms Coscinodiscus sp. and Thalassiosira eccentrica were attached to glass coverslips and placed in a small flow chamber. The chamber design was modified from those commonly used in biofilm studies (Korber et al. 1990). Flow cells were constructed from 2 perspex slides separated by a $2.5 \mathrm{~mm}$ thick o-ring. One slide had an ellipse cut from it (major axis $=15 \mathrm{~mm}$, minor axis $=10 \mathrm{~mm}$ ) and a coverslip was placed over the hole and sealed against the o-ring by 4 small screws joining the perspex slides. Tubing was connected to two $23 \mathrm{G}$ syringe needles, which were pushed through the o-ring and into the chamber. The solution containing the particles was pumped through one needle and out the other and flow was controlled using a peristaltic pump. Live and dead diatom cells were stuck on the underside of the coverslip with poly-lysine (Marchant \& Thomas 1983), and movements of beads over the frustules of diatoms were determined by video microscopy. To allow comparison between beads moving over a frustule with those over a flat surface, beads were also recorded moving over a glass coverslip. Video microscopy also allowed measurements of flow speeds, $20 \mu \mathrm{m}$ above the surface and the confirmation of laminar flow in the region of the chamber being examined.

Artificial seawater solutions $\left(35 \%, 20^{\circ} \mathrm{C}\right.$, filtered through $0.24 \mu \mathrm{m}$ pore size) containing mono-disperse, charge-stabilised, spherical, fluorescent polystyrene (Molecular Probes) or latex (Sigma) beads with radii of $0.05,0.1,0.15,0.25,0.3,0.4,0.5$ or $1 \mu \mathrm{m}$, were used for experiments. $\mathrm{NaCl}$ in solution screened electrostatic interactions to approximately $4 \mathrm{~nm}$, the Debye-Huckel screening length (Kaplan et al. 1994). Interactions between pairs of beads have been shown to alter bead diffusion (Batchelor 1976, Crocker 1997). To ensure that interactions between beads were negligible, the concentration of beads was such that the average separation distance was always larger than $16 \mu \mathrm{m}$ (Feitosa $\&$ Mesquita 1991). Flow rates of 0,50, 100 and $800 \mu \mathrm{m}$ $\mathrm{s}^{-1}$, measured $20 \mu \mathrm{m}$ above the surface, were established. Chambers were viewed under Nomarski optics and fluorescence video microscopy using a 100× oil immersion objective (numerical aperture $=1.3$ ), with further magnification provided by 3.3 or 6.7 long dis- tance coupling lenses to a Panasonic CCD camera (WV-BP550). Only the beads that were in focus were included in the analysis. Due to the depth of field of the objective, this ensured that beads were no more than $1 \mu \mathrm{m}$ from the surface.

With no flow, deviations from unbiased Brownian motion were quantified by analysing video footage of beads, frame by frame $(1 / 25 \mathrm{~s}$ intervals) for $5 \mathrm{~s}$. We measured the distance of beads from the centre of the ridged areas surrounding each areola, and calculated the proportion of time that beads spent on the ridged areas. The proportion of time that beads spent on the ridged areas surrounding the areolae was measured from 130 sequential frames of video footage, for each bead-surface combination. Experiments were repeated 5 times, each with a different diatom frustule to account for minor shape variation that occurs among the individual frustules of one species. For control data, beads diffusing over a flat glass surface were viewed frame by frame, with a 2-dimensional diatom surface structure of each species superimposed on the video screen. This procedure ensured that observed localisations of beads on ridged areas were due to the presence of diatom frustules, rather than an artefact due to differences in relative amounts of ridged and unridged areas of each species. Sequential positions of the beads on the frustule surface, described above, were also used to calculate the probability that beads remained on the ridged areas of frustules after diffusing there.

Under flow, deviations of bead movement from the direction of flow were determined using frame-byframe analysis of video footage of beads moving across frustule surfaces and over flat glass slides. To ensure that location and orientation information from adjacent frames were statistically independent, we plotted autocorrelograms of the trajectory angle and found that there were no significant autocorrelations between frames. The sequential positions of beads were also used to determine bead speed and the angle of deflection of beads from the direction of flow.

Diffusion. The successive position of each bead was recorded for 1000 frames $(20 \mathrm{~s})$ for the 0.5, 1 and $2 \mu \mathrm{m}$ beads and 100 frames $(2 \mathrm{~s})$ for the 0.1 and $0.2 \mu \mathrm{m}$ beads, as the smaller bead sizes were difficult to resolve and rapidly disappeared from the focal plane. Video sequences were digitised to computer memory at 50 frames s ${ }^{-1}$ (IMAQ PCI-1408 monochrome image acquisition board, National Instruments, Austin, TX, USA). The resulting digital filmstrips were analysed frame by frame for trajectories of movement by LabTrack (DiMedia, Kvistgaard, Denmark) (Blackburn et al. 1998). For each bead-surface combination, 10 bead paths were captured in each of 3 replicate chambers. The square of the displacement from each bead's original position was calculated and the average square of the displace- 
ment (i.e. over 10 beads) was plotted as a function of time. The diffusion coefficient was calculated from the slope of the linear fit of the statistical average by dividing the slope by 4 (Faucheux \& Libchaber 1994).

\section{RESULTS}

Beads were observed diffusing across the ridged areas surrounding the areolae of frustules, for some bead sizes. The size range of beads significantly affected by the presence of a frustule differed between Coscinodiscus sp. and Thalassiosira eccentrica (Fig. 2) and was not statistically significant for all bead sizes. For example, significant localisations of $0.05 \mu \mathrm{m}$ beads were seen over the ridged areas of Coscinodiscus sp. frustules; however, no significant localisations of $0.05 \mu \mathrm{m}$ beads were observed over the ridges of $T$. eccentrica frustules (Fig. 2A compared to Fig. 2D). Beads with radii of 0.05 to $0.5 \mu \mathrm{m}$ were significantly localised on the ridged areas surrounding areolae of

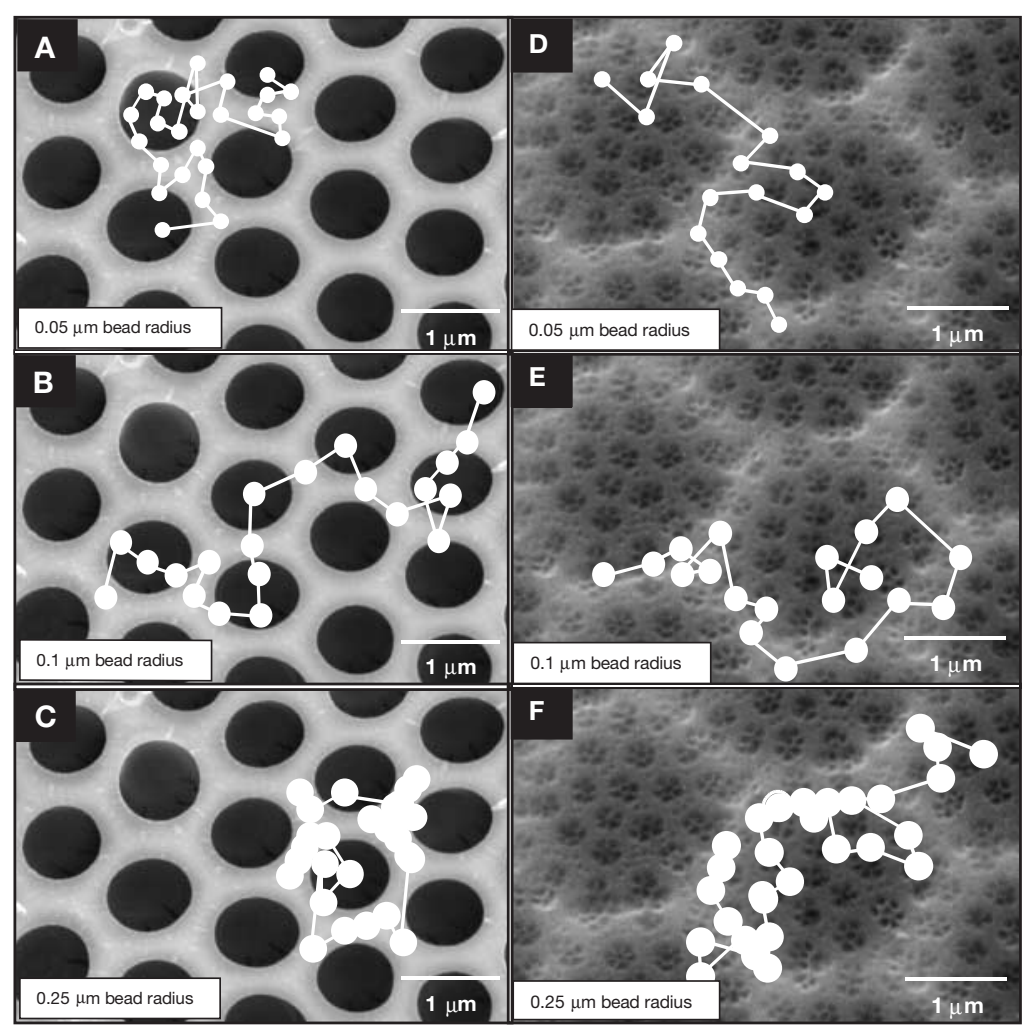

Fig. 2. Diagrammatic examples of bead paths over the surfaces of live (A-C) Thalassiosira eccentrica and (D-F) Coscinodiscus sp. with no flow. For each surface-bead combination, sequential frames of video footage $(t=0.04 \mathrm{~s}$ between frames) were viewed on a monitor and tracings were made of both the frustule surface and the bead path. Due to the regular nature of the areolation patterns of frustules, we were able to transcribe bead paths onto scanning electron micrographs of acid-washed frustule surfaces, with circles representing the position of the centre of each bead $( \pm 0.06 \mu \mathrm{m})$, in sequential frames both live and dead Coscinodiscus sp. (Fig. 3A, insert). Fig. 3A shows the proportion of time that $0.25 \mu \mathrm{m}$ radii beads spent at each distance from the centre of the ridged areas. For example, $0.25 \mu \mathrm{m}$ beads diffusing over the surface of live Coscinodiscus sp. spent $36 \%$ of their time diffusing over the ridged areas, compared to $17.1 \%$ on the superimposed 'ridges' of the control experiments over glass slides. Thus, $0.25 \mu \mathrm{m}$ beads spent 2.1 times as long diffusing over ridged areas and had 1.5 times the probability of remaining on the ridged areas as those diffusing over glass slides (Fig. 3A). In the case of T. eccentrica, beads with radii of 0.15 to $0.5 \mu \mathrm{m}$ were significantly affected by the frustules of both live and dead cells (Fig. 3A, insert). Fig. 3B shows that the localisation was strongest when the bead radius (a) was much smaller than the radius of the areolae $\left(R_{\mathrm{o}}\right)$. The smallest ratio tested in our experiments was $a / R_{\mathrm{o}}=0.05$.

Experimentally determined diffusion coefficients of beads with radii of 0.1 to $0.5 \mu \mathrm{m}$ diffusing over diatom frustules were significantly lower than for beads diffusing over flat glass surfaces $(p<0.001)$ (Fig. 4A). Reductions in bead diffusion showed a linear relationship with the bead-to-areola ratio $\left(a / R_{\mathrm{o}}\right)$ (Fig. $\left.4 \mathrm{~B}\right)$, with the smallest values of $a / R_{\mathrm{o}}$ producing the greatest reduction in diffusion.

Under flow, velocities of beads moving over diatom frustules were up to an order of magnitude slower over than over flat glass. The greatest velocity difference was seen for $0.25 \mu \mathrm{m}$ radii beads at the highest flow velocity of $800 \mu \mathrm{m} \mathrm{s}^{-1}$. Bead velocity across the flat glass surface was $254 \pm 5 \mu \mathrm{m} \mathrm{s}^{-1}$ and was reduced to $25 \pm 1.0 \mu \mathrm{m} \mathrm{s}^{-1}$ across the surface of Coscinodiscus sp. (Fig 5). In addition to reduced velocities, beads moving across diatom surfaces were deflected away from the direction of flow (Fig. 5). Up to $60 \%$ of particles were shifted more than $20^{\circ}$ from the direction of flow, with some shifted up to $170^{\circ}$, resulting in dispersal of particles across the surface (Fig. 6). In contrast to this $170^{\circ}$ maximum shift, beads moving over flat glass surfaces were deflected a maximum of $10^{\circ}$ from the direction of flow.

\section{DISCUSSION}

The frustules of live diatoms and acid-cleaned frustules had similar and significant effects on the diffusion of 

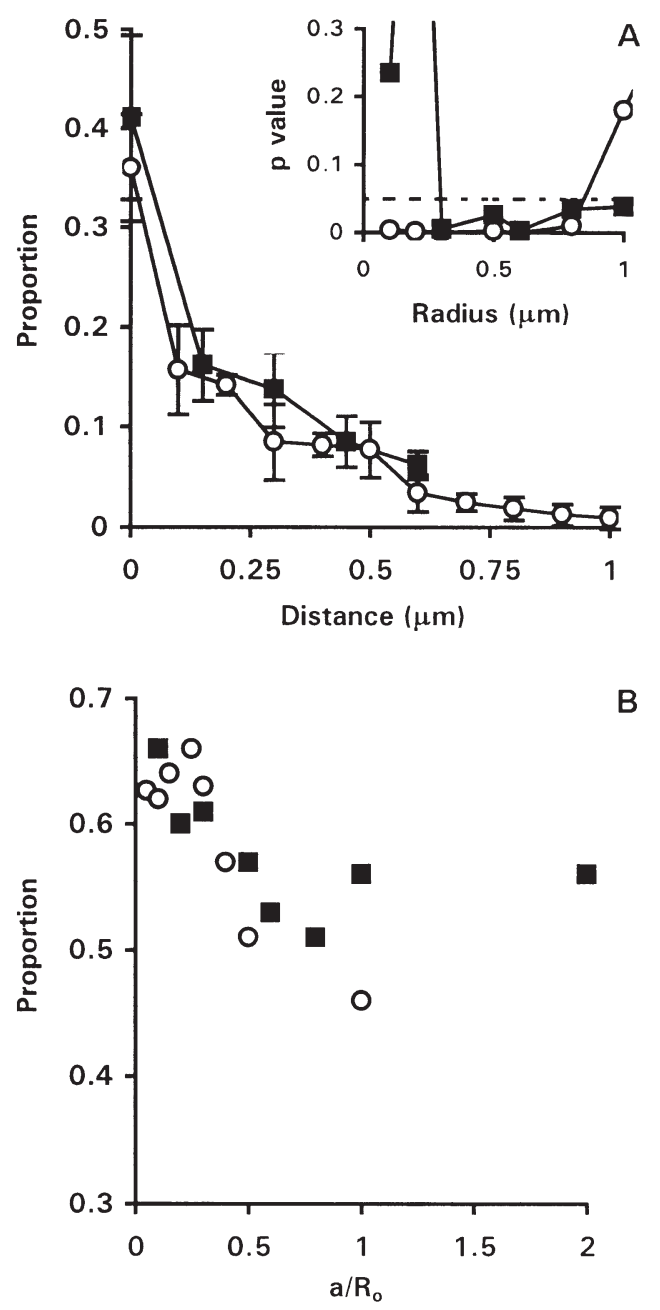

Fig. 3. (A) An example of the localisation of beads over the ridged areas surrounding areolae. The $x$-axis represents the horizontal distance from the centre of the ridge to the centre of the areola. Beads with radii of $0.25 \mu \mathrm{m}$ were localised on the ridges of both Coscinodiscus sp. (o) and Thalassiosira eccentrica (घ) and spent less time diffusing in the centre of the areolae. Data are means for live cells and error bars represent $95 \%$ confidence intervals $(n=5)$. Inset shows the $p$-values of ANOVAs, testing for significant differences in the proportion of time beads spent diffusing over the ridged areas of live Coscinodiscus sp. and T. eccentrica frustules, compared to behaviour of controls. Data points lying below the dashed line show where significant differences were observed. The $p$ values were the same for the probability that beads remained on the ridged areas, with the exception that the probability that $0.5 \mu \mathrm{m}$ beads remained on the ridged areas of Coscinodiscus sp. was also significantly different from the control. There were no significant differences observed in the behaviour of beads over live and dead cells of each species, with the exceptions of $0.25 \mu \mathrm{m}$ beads diffusing over dead Coscinodiscus sp. and $0.1 \mu \mathrm{m}$ beads diffusing over dead T. eccentrica cells. In both cases, beads spent significantly higher proportions of time on the ridged areas of dead cells than live ones ( $p<0.01)$. (B) The proportion of time beads spent on the ridged areas of live diatom cells, as a function of the bead-toareola radii $\left(a / R_{\mathrm{o}}\right)$. Symbols represent the 2 diatom species as described above
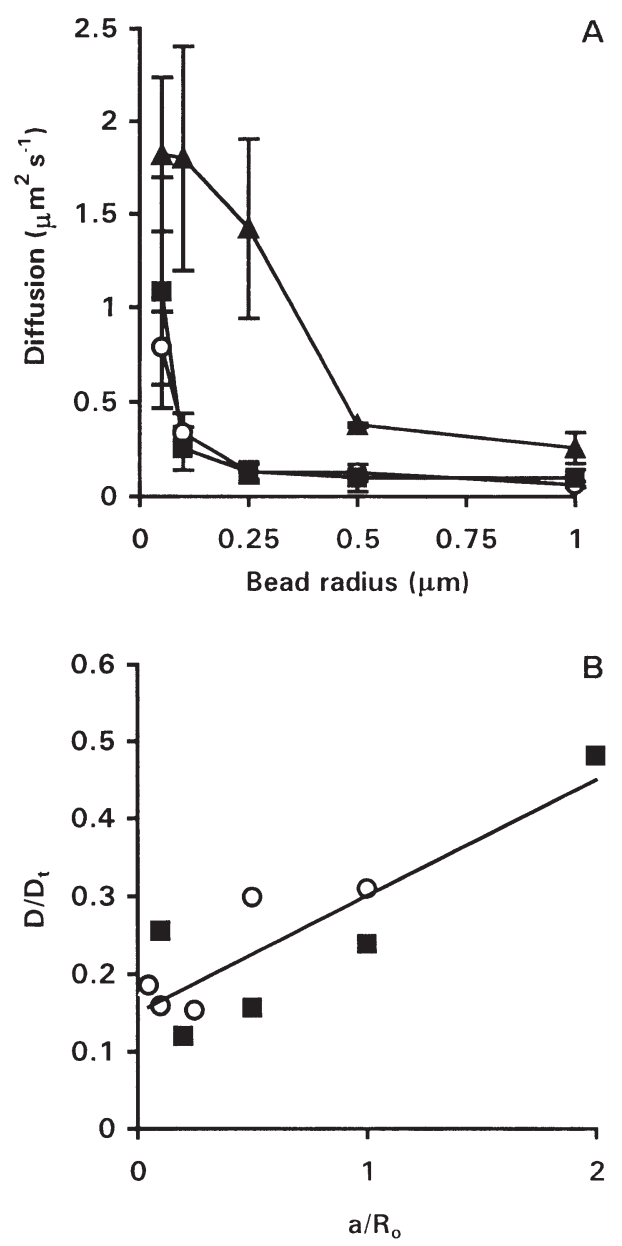

Fig. 4. (A) Diffusion coefficients of beads moving over the frustules of live Coscinodiscus sp. (0), Thalassiosira eccentrica (घ), and a glass slide ( $\mathbf{\Delta})$. Beads with radii 0.1 to $0.5 \mu \mathrm{m}$ diffused significantly slower over the frustules of both diatoms compared to those diffusing over glass and mid-chamber $(\mathrm{p}<0.01)$. Error bars are standard deviations $(n=3)$. (B) The effect of areolae on relative bead diffusion $\left(D / D_{\mathrm{t}}\right)$ as a function of the ratio of beadto-areola radii $\left(a / R_{0}\right)$, where $D$ is the experimentally determined diffusion and $D_{\mathrm{t}}$ is the theoretical diffusion coefficient for beads diffusing in an unbounded medium. Equation of the fitted trendline is $D / D_{\mathrm{t}}=0.15\left(\mathrm{a} / R_{\mathrm{o}}\right)+0.15\left(\mathrm{R}^{2}=0.72\right)$

Brownian particles as they moved across the surface, resulting in localised concentrations of particles on the ridged areas surrounding the areolae. For particles diffusing across a diatom frustule, along-ridge movement was more likely than cross-ridge movement, with the net result that ridges acted as conduits for particles, even in the presence of flow (see below).

Localisations of Brownian particles on flat plates and step edges have been reported previously (Kaplan et al. 1994, Dinsmore et al. 1996); however, these systems use binary mixtures with a few large beads in a high concentration of small beads. Localised entropic force fields are created when a large sphere approaches a 

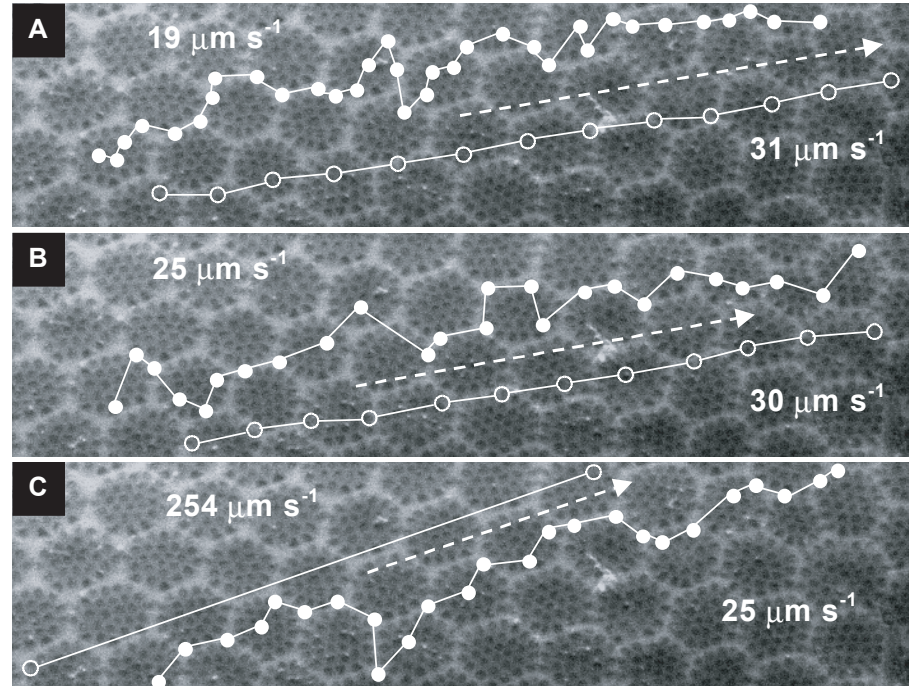

Fig. 5. Diagrammatic examples of bead paths for $0.25 \mu \mathrm{m}$ beads over live Coscinodiscus sp. at 3 different bulk flow rates: (A) 50 , (B) 100 and (C) $800 \mu \mathrm{m} \mathrm{s}^{-1}$. Bead paths were traced and transcribed onto scanning electron micrographs as described previously. Closed circles represent the position of the bead centre in sequential frames of video $(t=0.04 \mathrm{~s}$ between frames) and open circles represent the paths of beads moving over a flat glass slide. The direction of bulk flow (measured $20 \mu \mathrm{m}$ above the surface) is shown as the dashed line. The deflection of beads away from the direction of flow by the presence of a frustule can be clearly seen at all 3 flow speeds. The velocities of beads as they moved over each surface are shown next to the corresponding bead paths

wall, thus increasing the volume available to the small particles and maximising the entropy of the system. In our experiments, however, beads of only one size were used; therefore, the effects of diatom frustule microstructures on bead diffusion and advection cannot be explained by entropic force field theory.

In this study, the localisations of beads observed on ridged areas of frustules were due to variations in the drag experienced by beads as they diffused across the frustule surface. Dagan et al. (1982) have shown that for a sphere diffusing across a flat surface towards a single circular pore, where the sphere is smaller than the pore, drag is greatest when the sphere is on the surface surrounding the pore and decreases as the sphere moves to the edge of the pore, with a minimum value at the centre of the pore opening. For spheres diffusing parallel to the surface, the effect is most significant close to the opening of the pore and when spheres are less than 5 sphere diameters away, perpendicular to the surface (Dagan et al. 1982). For diatom frustules, this means that diffusion of beads is slower over ridged areas than over areolae, resulting in beads spending proportionally more time diffusing over ridges and resulting in localised concentrations on ridges. This effect would be most significant for species with foramen opening to the outside, but was also seen

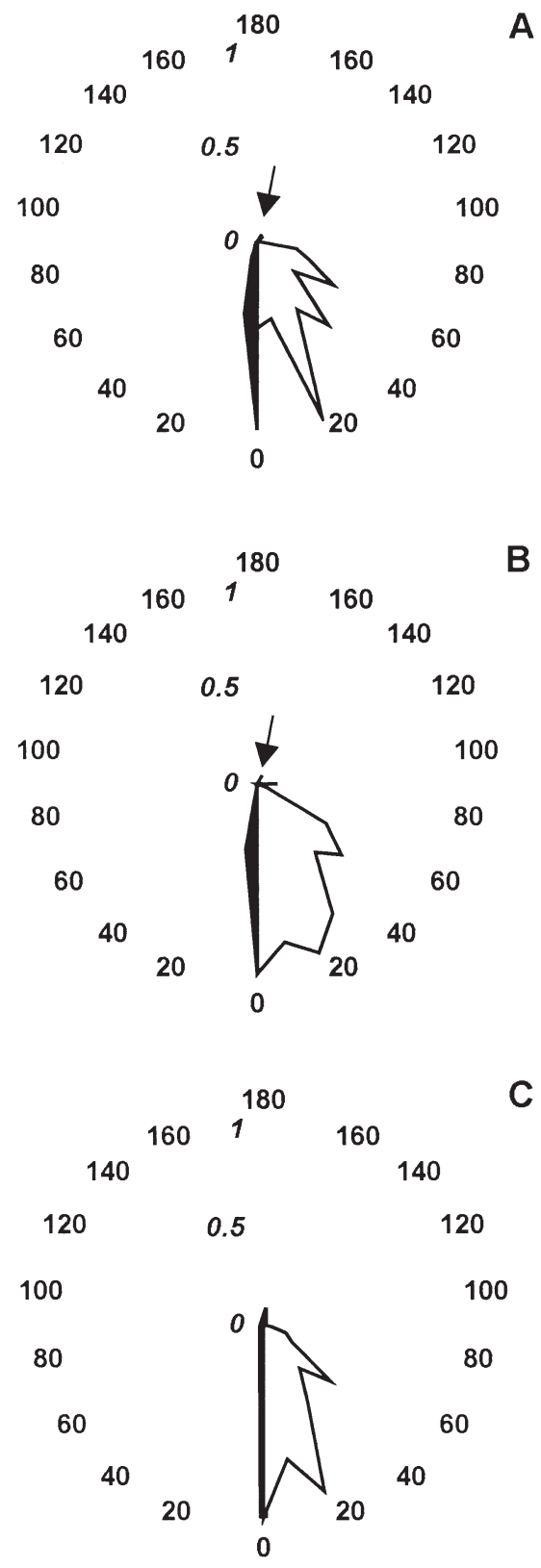

Fig. 6. Direction of $0.25 \mu \mathrm{m}$ bead movement, represented as deviations from the direction of flow $\left(0^{\circ}\right)$, over the frustules of live Coscinodiscus sp. (white) and over a flat glass surface (black), at 3 different flow rates, (A) 50, (B) 100 and (C) $800 \mu \mathrm{m}$ $\mathrm{s}^{-1}$. Circumference values are the angles of deviation, binned into $10^{\circ}$ classes. The maximum deviation observed was $170^{\circ}$. The scale in italics is the proportion of time that bead movement deviated from the direction of flow, for each directional bin. For visual comparison of beads flowing over both surfaces, data were normalised to the most frequently observed direction of particle movement for each surface. Three hundred frames of video footage $(11.5 \mathrm{~s})$ were viewed for each surface, at each speed $(n=3)$. All replicates gave similar results, but replicates were not averaged because angular shifts depended on the orientation of the diatom in the flow 
in Coscinodiscus sp., as the sieve plate covering the cell surface was thin, porous and recessed into each areola. As frustules are covered with regular arrays of closely spaced areolae, the drag experienced by beads varies consistently across the entire surface and may alter the diffusion of Brownian particles up to $5 \mu \mathrm{m}$ above the frustule (Dagan et al. 1982). This distance is much larger than $4 \mathrm{~nm}$, the maximum distance that electrostatic forces operate.

Our data show that for small values of $a / R_{0}$, beads spent a higher proportion of time diffusing over the ridged areas of frustules. This result is in agreement with models developed by Miyazaki \& Hasimoto (1984) and Yan et al. (1987), who have examined the creeping motion of small spheres towards circular pores on flat plates. These models predict that the effect on particle diffusion is greatest when $a / R_{\mathrm{o}}$ is small (0.1), that is, when the radius of the sphere is much smaller than the radius of the pore.

Small values of $a / R_{\mathrm{o}}$ also had the greatest reduction of diffusion. For the 2 species studied here, our results show that the foramen-ridge complex of frustules causes size-specific drag maxima. Differential drag across the frustule of an individual diatom would result in the sorting of particles at the frustule surface and may also operate to sort smaller particles at the porous sieve plate within the frustule. If sorting occurs at the sieve plate as well as at the ridge-areolar surface, as seems consistent with theory and our observations, then particle processing may be one of the primary functions of diatom frustules.

As well as affecting diffusion of particles close to the surface, the presence of areolae may also affect osmotic flux of particles, by altering concentration gradients close to surfaces. Results of a model developed by Yan et al. (1986) predicted that osmotic flux through a large, shallow pore may be overestimated by up to $200 \%$, for small particles $\left(a / R_{\mathrm{o}}=0.01\right)$, if effects of pores are not considered. Although we were unable to resolve particles with radii smaller than $0.05 \mu \mathrm{m}\left(a / R_{\mathrm{o}}\right.$ $=0.05-0.1$, Yan et al.'s (1986) model predicts that effects of areolae on osmotic flux would be greatest for particles with radii less than $10 \mathrm{~nm}$, the size range that includes potential nutrients.

If Yan et al.'s (1986) model predictions are correct, changes in the diffusion and osmotic flux of particles due to frustule microstructures may have important implications for nutrient uptake by diatoms. Previous studies modelling nutrient acquisition have considered phytoplankton as smooth spheres or spheroids (KarpBoss et al. 1996, Pahlow et al. 1997), despite the marked deviation from sphericity of most species and the diverse range of frustule areolation patterns. As the supply of nutrients occurs by diffusive and advective transport towards the cell surface, any effects of cell shape and surface morphology on diffusive and advective processes may have important implications for nutrient uptake and thus competition, particularly between species with different surface morphologies. Therefore it is inadequate to model cells as spheres with smooth surfaces, when attempting to determine the flux of particles and possibly nutrients, to diatoms.

Behaviour of particles moving across frustule surfaces was also altered in the presence of flow. This is important, because diatoms exist in an environment of continuous flow and, indeed, depend on flow to replenish nutrients in the surrounding water. Flow rates were measured $20 \mu \mathrm{m}$ above the surface of the frustules of Coscinodiscus sp. Therefore, as flow decreases fractionally from the surface of a sphere by:

$$
1-\left\{1-\left[\frac{3}{4 r}-\left(\frac{1}{4 r^{3}}\right)\right]\right\}
$$

where $r$ is the distance away from the surface (in units of sphere radii) (Stokes 1851, cf. Batchelor 1967), only $37 \%$ of the total shear occurs across the first $20 \mu \mathrm{m}$ distance from the surface of a cell with radius $50 \mu \mathrm{m}$. Thus, flow velocities of 50, 100 and $800 \mu \mathrm{m} \mathrm{s}^{-1}$, measured at $20 \mu \mathrm{m}$ away from the surface, correspond to velocities of 135, 270 and $2160 \mu \mathrm{m} \mathrm{s}^{-1}$, respectively. In the marine environment, cells experience flow as they sink through the water column and as they encounter Kolmogorov eddies. Typical sinking velocities for diatoms measured in the lab range from 30 to $300 \mu \mathrm{m} \mathrm{s}^{-1}$ (Smayda 1970). Villareal et al. (1996) have reported a maximum ascent rate of $1800 \mu \mathrm{m} \mathrm{s}^{-1}$ for vertically migrating Rhizosolenia mats observed in the field. Similarly, flow velocities calculated from energy dissipation rates $(\varepsilon)$ typical of the upper mixed layer $\left(\varepsilon=10^{-2}\right.$ to $10^{-4} \mathrm{~cm}^{2} \mathrm{~s}^{-1}$ ) range from 300 to $1000 \mu \mathrm{m} \mathrm{s}^{-1}$ (Mitchell et al. 1985, Karp-Boss et al. 2000). Therefore the 2 lowest flows used (135 and $270 \mathrm{\mu m} \mathrm{s}^{-1}$ ) are equivalent to flows that would be experienced by diatoms in the field, either as individual plankton, as chaining cells, cells attached to sinking particulate matter or to those forming mats. We included the highest flow of $2160 \mu \mathrm{m} \mathrm{s}^{-1}$ to show that this process works even if diatoms are at the surface of a large particle, on a moving animal or at the top of a biofilm in strong flow.

At the low Reynolds numbers of diatom frustules, when a particle approaches a flat surface, hydrodynamic interactions between the particle and the surface increase the viscous drag experienced by the particle (Brenner 1961, Walz \& Suresh 1995). The hydrodynamic resistance experienced by the particle can differ substantially from the Stokes resistance of a particle in an unbounded fluid (Yan et al. 1987), creating a region of shear between the wall and the fluid above. For phytoplankton, shear flow is already known to be important in determining near-surface nutrient 
dynamics (Karp-Boss et al. 1996) and the aggregation and disaggregation of colloids (Chin et al. 1998, Serra \& Casamitjana 1998), but there is no research on the mechanisms. We found that the presence of areolation patterns on diatom frustules in flowing seawater further reduced particle velocities by up to an order of magnitude from those over flat glass surfaces. In addition to reduced velocities, beads were deflected away from the direction of flow.

The reduction in particle velocities and the deflection of particles, compared with those measured for particles moving over a flat glass surface, suggest that vertical velocity profiles, and therefore the shear experienced by particles near the frustule surface, differ from those over a flat surface. This may result in the disaggregation of colloids and the release of dissolved nutrients close to the surface. Thus, frustule-pattern particle dispersion may enhance nutrient uptake. The hydrodynamic effects of areolae on shear flow can explain the deviation of particles from the direction of flow across the frustule. Models developed to examine shear flow over pores of different shapes, radii and depths have shown that pore morphology is important in determining the streamlines of flow (Pozrikidis 1994). For a shallow cylindrical pore at low Reynolds number, similar to the areolae of diatoms used in this study, streamlines follow the rim of the pore as water moves over the surface. This effect is limited to the region at the rim of the pore, where shear stresses change rapidly. At the down-stream edge of the rim, shear stresses return to the unperturbed values corresponding to simple shear flow over a flat surface (Pozrikidis 1994). As frustule surfaces are covered with regular arrays of closely spaced areolae, it is likely that shear flows remain perturbed over the entire surface. For diatom frustules, this means that beads following streamlines are directed around the edges of areolae and remain on the ridged areas of the frustule, resulting in deflections of beads from the direction of bulk flow. This behaviour was observed in video footage, where beads were seen to move along the ridged parts of the surface. Although other forces, such as shearinduced lift (Belfort et al. 1994), may act to transport particles vertically away from the surface, the limited depth of field used in this study meant that any beads affected by these force were not included in the analysis.

Diatom frustules altered both the diffusion and advection of microscopic and sub-microscopic particles. The magnitude of the effect was dependant on the ratio of the bead to areolae radii $\left(a / R_{0}\right)$, where smaller values of $a / R_{\mathrm{o}}$ resulted in greater localisations of beads on the ridged areas and larger reductions in diffusion than for higher values of $a / R_{0}$. Therefore the effect of the frustule surface on a particle of a certain size differs for species with different sized areolae.
This suggests that in areas of nutrient flux (i.e. areolae) the surrounding surface morphology may be capable of preselecting the material (macromolecules to bacteria) that reaches the cell membrane and its receptors, depending on the size of the particle and the radius of the areolae. By localising particles on the solid surfaces of their frustules, diatoms may be able to reduce clogging of areolae and effectively increase the surface area available for nutrient flux. As such, frustule surface structures and their effects on diffusive and advective processes may be crucial but overlooked factors in understanding cell growth dynamics and may help explain the diversity of frustule structures observed amongst diatoms. Furthermore, the ability of diatom frustules to passively control the diffusion and advection of particles makes their study potentially useful for understanding the interaction of particles with other microbe and animal surfaces, in more accurately predicting biofilm formation and even in the manufacture of a variety of nanotechnological devices for use in microfluidics and microfabrication.

Acknowledgements. The authors gratefully acknowledge the constructive comments of Peter Jumars and 3 anonymous reviewers. Funding for this research was provided by the Australian Research Council and Flinders University.

\section{LITERATURE CITED}

Ackerman HW, Dubow MS (1987) Viruses of prokaryotes. CRC Press, Boca Raton

Babanazarova OV, Likhoshway YV, Sherbakov DY (1996) On the morphological variability of Aulacoseira baicalensis and Aulacoseira islandica (Bacillariophyto) of Lake Baikal, Russia. Phycol 35:113-123

Batchelor GK (1967) An introduction to fluid dynamics. Cambridge University Press, Cambridge

Batchelor GK (1976) Brownian diffusion of particles with hydrodynamic interaction. J Fluid Mech 74:1-29

Belfort G, Davis RH, Zydney AL (1994) The behaviour of suspensions and macromolecular solutions in crossflow microfiltration. J Membrane Sci 96:1-58

Blackburn N, Fenchel T, Mitchell J (1998) Microscale nutrient patches in planktonic habitats shown by chemotactic bacteria. Science 282:2254-2256

Brenner H (1961) The slow motion of a sphere through a viscous fluid towards a plane surface. Chem Eng Sci 16: $242-251$

Chin W, Orellana MV, Verdunga P (1998) Spontaneous assembly of marine dissolved organic matter into polymer gels. Nature 391:568-572

Chou C, Bakajin O, Turner SWP, Duke TAJ, Chan SS, Cox EC, Craighead HG, Austin RH (1999) Sorting by diffusion: an asymetrical obstacle course for continuous molecular separation. Proc Natl Acad Sci USA 96:13762-13765

Crocker JC (1997) Measurement of the hydrodynamic corrections to the Brownian motion of two colloidal spheres. J Chem Phys 106:2837-2840

Dagan Z, Weinbaum S, Pfeffer R (1982) General theory for the creeping motion of a finite sphere along the axis of a circular orifice. J Fluid Mech 117:143-170 
Dinsmore AD, Yodh AG, Pine DJ (1996) Entropic control of particle motion using passive surface microstructures. Nature 383:239-242

Ducklow HW, Shiah F (1993) Estuarine bacterial production. In: Ford TE (ed) Aquatic microbiology: an ecological approach. Blackwell Scientific Publications, London, p 261-284

Duke TAJ, Austin RH (1998) Microfabricated sieve for the continuous sorting of macromolecules. Phys Rev Lett 80: $1552-1555$

Faibish RS, Elimelech M, Cohen Y (1998) Effect of interparticle electrostatic double layer interactions on permeate flux decline in crossflow membrane filtration of colloidal suspensions - an experimental investigation. J Coll Int Sci 204:77-86

Faucheux LP, Libchaber AJ (1994) Confined Brownian motion. Phys Rev E 49:5158-5163

Feitosa MIM, Mesquita ON (1991) Wall-drag effect on diffusion of colloidal particles near surfaces: a photon correlation study. Phys Rev A 44:6677-6685

Fogg GE, Thake B (1987) Algal cultures and phytoplankton ecology. University of Wisconsin Press, Madison

Greville RK (1859) Descriptions of new species of British Diatomacæ, chiefly observed by the late Professor Gregory. Q J Microsc Sci 7:79-86

Hasle GR, Fryxell GA (1970) Diatoms: cleaning and mounting for light and electron microscopy. Trans Am Microsc Soc 89:469-475

Hasle GR, Syvertsen EE (1996) Marine diatoms. In: Tomas K (ed) Identifying marine diatoms and dinoflagellates. Academic Press, San Diego, p 5-386

Hennes KP, Suttle CA (1995) Direct counts of viruses in natural waters and laboratory cultures by epifluorescence microscopy. Limnol Oceanogr 40:1050-1055

Kaplan PD, Faucheux LP, Libchaber AJ (1994) Direct observation of the entropic potential in a binary suspension. Phys Rev Lett 73:2793-2796

Karp-Boss L, Boss E, Jumars P (1996) Nutrient fluxes to planktonic osmotrophs in the presence of fluid motion. Oceanogr Mar Biol Annu Rev 34:71-107

Karp-Boss L, Boss E, Jumars PA (2000) Motion of dinoflagellates in a simple shear flow. Limnol Oceanogr 45:1594-1602

Kaplan PD, Faucheux LP, Libchaber AJ (1994) Direct observation of the entropic potential in a binary suspension. Phys Rev Lett 73:2793-2796

Korber DR, Lawrence JR, Zhang L, Caldwell DE (1990) Effect of gravity on bacterial deposition and orientation in laminar flow environments. Biofouling 2:335-350

Kühn SF (1997) Rhizmoeba schnepfii sp. Nov., a naked amoeba feeding on marine diatoms (North Sea, German Bight). Arch Protistenkd 147:277-282

Editorial responsibility: Fereidoun Rassoulzadegan, Villefranche-sur-Mer, France
Marchant HJ, Thomas DP (1983) Polylysine as an adhesive for the attachment of nanoplankton to substrates for electron microscopy. J Microsc 131:127-129

Mitchell JG, Okubo A, Fuhrman JA (1985) Microzones surrounding phytoplankton form the basis of a stratified marine microbial ecosystem. Nature 316:58-59

Miyazaki T, Hasimoto H (1984) The motion of a small sphere in a fluid near a circular hole in a plane wall. J Fluid Mech 145:201-221

Pahlow M, Riebesell U, Wolf-Gladrow DA (1997) Impact of cell size and chain formation on nutrient acquisition by marine diatoms. Limnol Oceanogr 42:1660-1672

Pozrikidis C (1994) Shear flow over a plane wall with an axisymmetric cavity or circular orifice of finite thickness. Phys Fluids 6:68-79

Purcell EM (1977) Life at low Reynolds number. Am J Phys 45: $3-11$

Round FE, Crawford RM, Mann DG (1990) The diatoms, biology and morphology of the genera. Cambridge University Press, Cambridge

Serra T, Casamitjana X (1998) Structure of the aggregates during the process of aggregation and breakup under shear flow. J Coll Int Sci 206:505-511

Smayda TJ (1970) The suspension and sinking of phytoplankton in the sea. Oceanogr Mar Biol Annu Rev 8: 353-414

Song L, Elimelech M (1995) Particle deposition onto a permeable surface in laminar flow. J Coll Int Sci 173:165-180

van der Hoek C, Mann DG, Jahns HM (1995) Algae: an introduction to phycology. Cambridge University Press, Cambridge

Villareal TA, Woods S, Moore JK, Culverrymsza K (1996) Vertical migration of Rhizosolenia mats and their significance to $\mathrm{NO}_{3}$ fluxes in the Central North Pacific Gyre. J Plankton Res 18(7):1103-1121

Vogel (1983) Life in moving fluids. Princeton University Press, Princeton, NJ

Walz JY, Suresh L (1995) Study of the sedimentation of a single particle toward a flat plate. J Chem Phys 103: 10714-10725

Wells ML, Goldberg ED (1994) Occurrence of small colloids in the North Atlantic and Southern Oceans. Limnol Oceanogr 39:286-302

Yan Z, Weinbaum S, Pfeffer R (1986) On the finite structure of osmosis including three-dimensional pore entrance and exit behaviour. J Fluid Mech 162:415-438

Yan Z, Weinbaum S, Ganatos P, Pfeffer R (1987) The threedimensional hydrodynamic interaction of a finite sphere with a circular orifice at low Reynolds number. J Fluid Mech 174:39-68

Submitted: September 21, 2000; Accepted: March 20, 2001

Proofs received from author(s): June 26, 2001 